\title{
MODAL ANALYSIS METHOD FOR STIFFNESS DEGRADATION IDENTIFICATION OF NON- PROPORTIONALLY DAMPED STRUCTURES
}

\author{
Hong Ying YUAN*, Kiyoshi HIRAO**, \\ Tsutomu SAWADA*** \\ and Yoshifumi NARIYUKI****
}

\begin{abstract}
A modal analysis method is presented to identify both the location and the severity of stiffness degradation for nonproportionally damped structures by using measured lower modes. A ten-story shear building has been analyzed to demonstrate the availability of the method. Also the effects of measurement error of modes on identification accuracy has been examined.
\end{abstract}

Key Words : stiffness degradation, nonproportional damping, modal analysis method

\section{INTRODUCTION}

It is generally recognized that damage of structures caused by an earthquake etc. will result in degradation of stiffness and in change of damping. Many methods in time domain and frequency domain by the use of observed vibration record have been developed for detecting the damage of structures. However, someties the identification accuracy of those methods is greatly affected by noise ${ }^{1)}$. Also in civil engineering, the instrument for earthquake record is installed only in a small number of important structures, but not most structures. Therefore, an evaluation of damage through modal analysis methods ${ }^{2)}$ which are based on the measured modal parameters from ordinary vibration testing is paid increasing attentions.

In our previous studies ${ }^{3,4)}$, we dealt with the damage evaluation for a structure without damping or with proportional damping ${ }^{5}$. However, it is necessary to evaluate the damage of a structure with non-proportional damping ${ }^{5}$ which yields complex mode shapes, because non-proportional damping exists in realistic structures ${ }^{2)}$ e.g. cable-stay-bridges $^{6}$ or RC bridges with some deterioration ${ }^{7}$. In this study, a modal analysis method is presented to identify both the location

* M. Eng., Graduate Student, Dept. of Civil Eng., The University of Tokushima, Japan.

(2-1, Minamijosanjimacho, Tokushima, 770, Japan)

** Dr. Eng., Professor, Dept. of Civil Eng., The University of Tokushima, Japan.

*** Dr. Eng., Asso. Professor Dept. of Civil Eng., The University of Tokushima, Japan.

**** Dr. Eng., Lecturer, Dept. of Civil Eng., The University of Tokushima, Japan. and the severity of damage of a structure with nonproportional damping. The numerical result shows that this method has significant sensitivity for detecting the location of stiffness degradation. Also the effects of measurement error of modes on identification accuracy has been examined.

\section{MODAL ANALYSIS INSPECTION FOR NONPROPORTIONAL DAMPING}

A system with damping matrix $[C]$ which can not be considered as a proportional type is described by its free vibration equation of motion

$$
\begin{aligned}
& {[M]\{\ddot{Z}\}_{p}+[C]\{\dot{Z}\}_{p}+[K]\{Z\}_{p}=0 ;} \\
& p=1,2, \cdots, N
\end{aligned}
$$

where $[M]=$ mass matrix; $[C]=$ damping matrix; $[K]=$ stiffness matrix; $\{Z\}_{p}=$ the $p$ th vector of relative displacements and $N=$ the number of system's degree of freedom. The solutions of Eq.(1) can be expressed ${ }^{8)}$ as

$$
\left\{Z_{p}\right\}=\{X\}_{p} e^{\mu p t} ; p=1,2, \cdots, 2 N \cdots
$$

which $\left\{\mu_{p}\right\}=$ the $p$ th complex natural frequency and $\{X\}_{p}=$ the $p$ th complex eigenvector. Eq.(1) is rewritten as

$$
[M]\{X\}_{p} \mu_{p}^{2}+[C]\{X\}_{p} \mu_{p}+[K]\{X\}_{p}=0
$$

If Eq.(3) is premultiplied by the transpose of the complex conjugate of the complex mode shape $\{X\}_{p}$ i.e., $\{\bar{X}\}_{p}^{T}$, the system's free vibration equation of motion may be written alternatively as

$$
m_{p}{ }^{*} \mu_{p}^{2}+c_{p}{ }^{*} \mu_{p}+k_{p}^{*}=0
$$

where $m_{p}{ }^{*}, c_{p}{ }^{*}$ and $k_{p}{ }^{*}=$ real-value generalized parameters defined as 


$$
\left.\begin{array}{l}
m_{p}{ }^{*}=\{\bar{X}\}_{p}{ }^{T}[M]\{X\}_{p} ; \\
c_{p}{ }^{*}=\{\bar{X}\}_{p}{ }^{T}[C]\{X\}_{p} ; \\
k_{p}{ }^{*}=\{\bar{X}\}_{p}{ }^{T}[K]\{X\}_{p}
\end{array}\right\}
$$

Eq.(4) is thus an equation of $\mu_{p}$ with real coefficients whose solution yields ${ }^{9)}$

$$
\mu_{p}=-\xi_{p} \omega_{p}+i \omega_{p}^{\prime} ; \quad i^{2}=-1
$$

where

$$
\left.\begin{array}{l}
\omega_{p}=\sqrt{{k_{p}}^{*} / m_{p}^{*}} ; \\
\omega_{p}^{\prime}=\omega_{p} \sqrt{1-\xi_{p}^{2}} ; \\
\xi_{p}=c_{p} * / 2 \omega_{p} m_{p}^{*}
\end{array}\right\}
$$

The $\omega_{p}, \omega_{p}^{\prime}$ and $\xi_{p}$ represent the system's $p$ th undamped natural frequency, $p$ th damped natural frequency and $p$ th damping ratio respectively. Moreover, if the $1 \sim L$ th conjugate pairs of modes have been measured, the real- ${ }^{-}$art and imaginarypart of natural frequency matrix $[\Omega]$ and mode shape matrix $[\Phi]$ can be expressed as follows

$$
\begin{aligned}
{[\Omega]_{L \times L}=} & {[\Omega]_{a}+i[\Omega]_{b}=\operatorname{diag}\left[\mu_{1}, \mu_{2}, \cdots, \mu_{L}\right] } \\
{[\Phi]_{N \times L}=} & {[\Phi]_{a}+i[\Phi]_{b}=\left[\{X\}_{1},\{X\}_{2},\right.} \\
& \left.\cdots,\{X\}_{L}\right]
\end{aligned}
$$

A commonly used, nonproportional damping matrix with sufficient accuracy ${ }^{5)}$ is defined as

$$
[C]=\beta_{0}[I]+\beta_{1}[M]+\beta_{2}[K]
$$

where, $\beta_{0}(\neq 0), \beta_{1}$ and $\beta_{2}=$ the coefficents regarding to damping; $[I]=$ identity matrix. It should be noted that the $\beta_{0}, \beta_{1}$ and $\beta_{2}$ may be determined experimentally ${ }^{10)}$.

Let $[K]=\left[K_{0}\right]+[\Delta K]$, in which $\left[K_{0}\right]$ is undamaged stiffness matrix and $[\Delta K]$ is the change of stiffness before and after damage. Substituting the $[\Omega],[\Phi],[M],[C]$ and $[K]$ into Eq.(3), and then arranging the obtained equations, the separated real-part and imaginarypart of the equations can be obtained, respectively. The equations for the real-part is

$$
[\Delta K]\left[\Gamma_{1}\right]=\left[\Xi_{1}\right]
$$

where $\left[\Gamma_{1}\right]_{N \times L}=\left(\beta_{2}[\Phi]_{a}[\Omega]_{a}-\beta_{2}[\Phi]_{b}[\Omega]_{b}+\right.$ $\left.[\Phi]_{a}\right)$ and $\left[\Xi_{1}\right]_{N \times L}=-\beta_{0}\left([\Phi]_{a}[\Omega]_{a}-[\Phi]_{b}\right.$ $\left.[\Omega]_{b}\right)-[M]\left([\Phi]_{a}\left[\Omega^{2}\right]_{a}-[\Phi]_{a}\left[\Omega^{2}\right]_{b}-2[\Phi]_{b}\right.$ $\left.[\Omega]_{a}[\Omega]_{b}\right)-\beta_{1}[M]\left([\Phi]_{a}[\Omega]_{a}-[\Phi]_{b}[\Omega]_{b}\right)-$ $\left[K_{0}\right]\left[\Gamma_{1}\right]$.

Also the equations for the imaginary-part is

$$
[\Delta K]\left[\Gamma_{2}\right]=\left[\Xi_{2}\right]
$$

where $\left[\Gamma_{2}\right]_{N \times L}=\left(\beta_{2}[\Phi]_{b}[\Omega]_{a}+\beta_{2}[\Phi]_{a}[\Omega]_{b}+\right.$ $\left.[\Phi]_{b}\right)$ and $\left[\Xi_{2}\right]_{N \times L}=-\beta_{0}\left([\Phi]_{a}[\Omega]_{b}+[\Phi]_{b}\right.$ $\left.[\Omega]_{a}\right)-[M]\left([\Phi]_{b}\left[\Omega^{2}\right]_{a}-[\Phi]_{b}\left[\Omega^{2}\right]_{b}+2[\Phi]_{a}\right.$
$\left.[\Omega]_{a}[\Omega]_{b}\right)-\beta_{1}[M]\left([\Phi]_{b}[\Omega]_{a}+[\Phi]_{a}[\Omega]_{b}\right)-$ $\left[K_{0}\right]\left[\Gamma_{2}\right]$.

Eq.(10) and Eq.(11) can be further expressed as $[\Delta K]\left[\left[\Gamma_{1}\right],\left[\Gamma_{2}\right]\right]=\left[\left[\Xi_{1}\right],\left[\Xi_{2}\right]\right]$

The least-square estimate ${ }^{11)}$ of $[\Delta K]$ in the sense of trace $\left\{\left([\Delta K]\left[\left[\Gamma_{1}\right],\left[\Gamma_{2}\right]\right]-\left[\left[\Xi_{1}\right],\left[\Xi_{2}\right]\right]\right)^{T}\right.$ $\left.\left([\Delta K]\left[\left[\Gamma_{1}\right],\left[\Gamma_{2}\right]\right]-\left[\left[\Xi_{1}\right],\left[\Xi_{2}\right]\right]\right)\right\}$ to reach the minimum value is

$$
[\Delta K]=\left[\left[\Xi_{1}\right],\left[\Xi_{2}\right]\right]\left[\left[\Gamma_{1}\right],\left[\Gamma_{2}\right]\right]^{+}
$$

where $\left[\left[\Gamma_{1}\right],\left[\Gamma_{2}\right]\right]^{+}=$the pseudoinverse matrix ${ }^{11)}$ of $\left[\left[\Gamma_{1}\right],\left[\Gamma_{2}\right]\right]$.

The estimated $[\Delta K]$ can be used to detect the location of damage. Differing from the method for undamped and proportional damping problem which lead to a normal (real) mode shape ${ }^{8)}$, the method in this study for nonproportional damping problem has a better sensitivity to detect the degradation of stiffness. In fact, while there are $N(N+1) / 2$ unknown coefficents of $[\Delta K]$ and $N \times$ $L$ equations in Eq.(10) for undamped problem, there are $2 \times N \times L$ equations (see Eq.(12)) and $N(N+1) / 2$ unknown coefficents of $[\Delta K]$ in Eq.(13).

\section{SOLUTION OF UNKNOWN CO- EFFICIENTS}

The percentage of change ratio $\Delta k_{p p} / k_{0 p p}(p=1$, $2, \cdots, N)$ for diagonal stiffness coefficients can be used to detect the location of damage. When a node with a remarkable change ratio is detected, each non-zero stiffness coefficient in the column (or row) corresponding to this node in stiffness matrix $[K]$ is multiplied by an unknown coefficient $\alpha_{k}$ respectively. The total number of $\alpha_{k}$ is written as $N F$, thus the $[K]$ is expressed as $[K(\alpha)]$, where $\{\alpha\}=\left\{\alpha_{1}, \alpha_{2}, \cdots, \alpha_{N F}\right\}^{T}$. In Eq.(3), there are $N$ equations corresponding to each mode. If all those $L$ measured modes are used, the $L \times N$ equations can be obtained. Substituting the measured $\left[\Omega^{2}\right]$, $[\Phi]$, together with $[M],[C(\alpha)]$ and $[K(\alpha)]$ into Eq.(3), further arranging the $L \times N$ equations, the following new equations are obtained

$[A]\{\alpha\}=\{B\}$

where, $[A]$ and $\{B\}$ are known $N F \times N F$ matrix and $N F \times 1$ vector, respectively. After all the unknown coefficients $\{\alpha\}$ are solved, the $[K(\alpha)]$ is the identified result of $[K]$. Therefore, the severity of damage can be identified.

\section{NUMERICAL EXAMPLE}

A numerical example ${ }^{9)}$ of a ten-story shear building is shown in Fig.1. The structure is described as a FEM model with 11 nodes, 10 elements and 10 degrees of freedoms. Also the 


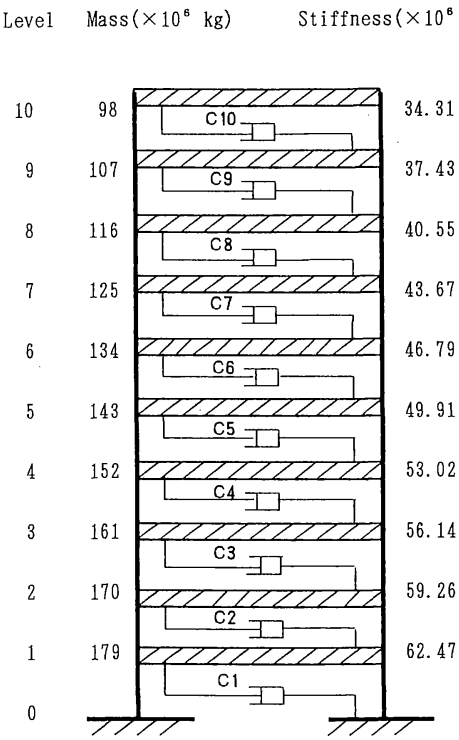

Fig.1 Ten-story shear building

Table 2 Identified coefficents of $[K]$; unit : $10^{6} \times \mathrm{N} / \mathrm{m}$

\begin{tabular}{|l|r|r|r|r|}
\hline \multicolumn{3}{|c|}{ BEFORE DAMAGE } & \multicolumn{3}{|c|}{ AFTER DAMAGE } \\
\hline NODE & EXACT & EXACT & \multicolumn{1}{c|}{ IDENT. } & $E_{P D}$ \\
\hline$k_{22}$ & 113.400 & 98.558 & 98.558 & 0.0 \\
\hline$k_{23}$ & -56.140 & -44.910 & -44.910 & 0.0 \\
\hline$k_{33}$ & 109.160 & 92.318 & 92.318 & 0.0 \\
\hline$k_{77}$ & 84.220 & 72.055 & 72.055 & 0.0 \\
\hline$k_{78}$ & -40.550 & -32.440 & -32.440 & 0.0 \\
\hline$k_{88}$ & 77.980 & 65.815 & 65.815 & 0.0 \\
\hline
\end{tabular}

order of nodes agrees with the numbered levels in the model. The undamped natural frequencies and damping ratios of the structure are listed in Table 1. In this example, it is assumed that, a damage occurs in element 3 (level 2-3) and element 8 (level 7-8). Therefore, the coefficents of stiffness in nodes 2, 3, 7 and 8 corresponding to those elements will be degraded. An approximate $15 \%$ minor degradation of stiffness is considered in those nodes. Moreover, referring to the study ${ }^{5}$, the coefficents regarding to damping $\beta_{0}, \beta_{1}$ and $\beta_{2}$ are taken as the known values in this study, i.e. $\beta_{0}=1$, $\beta_{1}=1.31 \times 10^{-1}$ and $\beta_{2}=5.47 \times 10^{-3}$. For both before and after the damage, the calculated modal parameters are hereby taken as the measured ones. Furthermore, from observing Fig.2 in which the nodes 2, 3, 7 and 8 are remarkable, the locations of damage are detected by using $1 \sim 4$ th measured

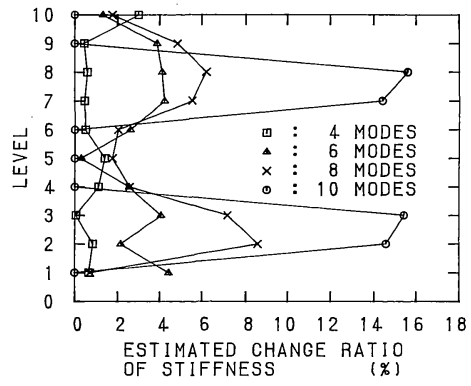

Fig.3 Damage location detection of previous study ${ }^{3}$ for undamped structures.

Table 1 Natural frequencies and damping ratios

\begin{tabular}{|c|c|c|c|c|}
\hline \multicolumn{3}{|c|}{ BEFORE DAMAGE } & \multicolumn{2}{c|}{ AFTER DAMAGE } \\
\hline $\mathrm{N}$ & $f_{p}(\mathrm{~Hz})$ & $\xi_{p}$ & $f_{p}(\mathrm{~Hz})$ & $\xi_{p}$ \\
\hline 1 & 0.500 & 0.020 & 0.480 & 0.054 \\
\hline 2 & 1.326 & 0.020 & 1.264 & 0.037 \\
\hline 3 & 2.151 & 0.027 & 2.097 & 0.035 \\
\hline 4 & 2.934 & 0.035 & 2.838 & 0.051 \\
\hline
\end{tabular}
on $E_{m}$ for thes nonproportional damping.

modes. Fig. 3 is the result of the detection of our previous method $^{3)}$ by using the $1 \sim 10$ th measured modes. In Fig.3, even if 8 modes are used, it seems there are stiffness changes in almost all the nodes. On the contrary, this method is significantly sensitive (see Fig.2). By the same way as stated in Section 3, the severity of damage can be identified. A percentage error $E_{p p}$ and a mean error $E_{m}$ of diagonal stiffness coefficients are defined as

$$
\begin{aligned}
E_{p p}= & \left|\left\{\left(k_{p p}\right)_{\mathrm{EXACT}}-\left(k_{p p}\right)_{\mathrm{IDENT} .}\right\} /\left(k_{p p}\right)_{\mathrm{EXACT}}\right| \\
& \times 100 ; \\
E_{m}= & \left(\sum E_{p p}\right) / N D
\end{aligned}
$$

where the $N D$ is the number of diagonal unknown stiffness coefficients among the $N F$ (the total number of $\alpha_{k}$ ). The calculated $E_{p p}$ and identified result are shown in Table 2 , in which the identified result is well satisfied. Moreover, the mean error $E_{m}$ of identification is shown in Fig.4. Referring to the report ${ }^{12)}$, two kinds of measurement errors (Error 1 and Error 2) for all the measured modal parameters (natural frequencies, mode shapes and 
damping ratios) are assumed in this study. The Error 1 is defined : Each measured value varies with a same percentage of the value. The Error 2 for mode shape is defined : If a percentage of the measured value is increased/or decreased in one node, the same percentage is decreased/or increased in the neighbour nodes. Also the Error 2 for natural frequency or damping ratio is defined : If a percentage of the measured value is increased/or decreased in a certain order, the same percentage is decreased/or increased in the neighbour order. The calculated results for the two kinds of errors show that the measurement error of mode shape has a strong effect on identification accuracy. On the other hand, damping ratio has a comparatively weak one. However, as for the measurement error of modal parameters on damage location detection, in this example, the detected locations remain unchanged within $20 \%$ measurement error of modes.

\section{CONCLUSIONS}

(1) This study presents a modal analysis method which can be applied to nonproportional damping. By this method, both the location and severity of damage can be identified.

(2) The method for nonproportional damping problem may have better sensitivity than the undamped or proportional one.

(3) The measurement error of mode shape has a strong effect on identification accuracy. On the contrary, that of damping ratio has a comparatively weak one. As for the measurement error of modal parameters on damage location detection for nonproportional damping, the detected locations remain unchanged within a certain range of measurement error of modes.

Moreover, the calculated results show that a sensitivity for detecting the location of damage is not affected by $\beta_{0}\left(\beta_{0} \neq 0\right.$, see Eq.(9)). Therefore, considering the conclusion (2), the sensitivity may be significantly improved by treating a damped structure (usually with Rayleigh damping) to be a nonproportionally damped one which is close to the structure with Rayleigh damping, i.e., $\beta_{0} \fallingdotseq 0$.

\section{REFERENCES}

1) Agbabian, M.S., Masri, S.F., Miller, R.K. and Caughey, T.K. : System identificaion approach to detection of structural changes, J. Engrg, Mech., Vol.117, No.2, ASCE, pp.370 390, Feb., 1991.

2) Tong, M., Liang, Z. and Lee, G.C. : Correction criteria of finite element modeling in structural dynamics, J. Engrg. Mech., Vol.118, No.4, ASCE, pp.663 682, Apr., 1992.

3) Yuan, H.Y., Hirao, K., Sawada, T. and Nariyuki, Y. : Detection of stiffness degradation of structural elements from measurement of natural frequencies and mode shape, J. Struct. Engrg., Vol.39 A, JSCE, pp.759 771, March, 1993.

4) Yuan, H.Y., Hirao, K., Sawada, T. and Nariyuki, Y. : Stiffness degradation identification of structures using modal analysis, J. Struct. Engrg., Vol.40 A, JSCE, March, 1994.

5) Liang, Z. and Lee, G.C. : Representation of damping matrix, J. Engrg. Mech., Vol.117, No.5, ASCE, pp.1005 1020, May, 1991.

6) Pacheco, M., Fujino, Y. and Sulekh, A. : Estimation curve for modal damping in stay cables with viscous damper, J. of Struc. Engrg., Vol.119, No.6, June, ASCE, 1993, pp.1961 $\sim 1979$.

7) Raghavendrachar, M. and Aktan, A.E. : Flexibility by multireference impact testing for bridge diagnostics, J. Struc. Engrg., Vol.118, No.8, Aug., 1992, ASCE, pp.2186 $\sim 2203$.

8) Togawa, H. : Vibrational analysis for finite element method, Science Book Company, 1975 (in Japanese).

9) Villaverge, R. and Koyama, L.A. : Damped resonant appendages to increase inherent damping in buildings, Earthquake Eng. Struct. Dyn., Vol.22, pp.491 517, June, 1993.

10) Liang, Z. and Lee, G.C. : On complex damping of MDOF systems, Proc. 8 th Int. Model Analysis Conf., Society for experimental Mechanics, pp.1048 1055.

11) Lowson, C.L. and Hanson, R.J. : Solving least squares problems, Prentice Hall, Englewood Cliffs, N.J., 1974.

12) Fukuoka, S., et al : A vibration testing of Yamato River Bridge, Bridge and Foundation Engineering, pp.24 30, March, 1984 (in Japanese).

(Received August 4, 1993)

モード解析による非比例減衰構造物の剛性劣化の同定

袁 紅茵・平尾 潔・沢田 勉・成行義文

本論文では, モ一ド解析により, 非比例減衰構造物が損傷をうけた場合の構造物構成 要素の剛性劣化を低次の測定モードを用いて同定する一手法を提案し, 数值計算例をも とに，本手法の適用性並びにモードの測定誤差が同定精度におよぼす影響について比較 検討している. 